\title{
Learning through practice: Collaborative policing partnerships in teaching in higher education
}

The Police Journal: Theory, Practice and Principles $1-17$

(C) The Author(s) 2019 Article reuse guidelines: sagepub.com/journals-permissions DOI: I0.I I77/0032258X| 9882056 journals.sagepub.com/home/pjx

@SAGE

\section{Katie Strudwick (1)}

School of Social and Political Sciences, University of Lincoln, Lincoln, UK

\begin{abstract}
This article discusses the development and good practice of an undergraduate collaborative partnership module between police practitioners and academics meeting the challenges for teaching partnerships within higher education. Through innovative curriculum design and the application of the Student as Producer model, the article considers aspects of student engagement, ownership of learning journeys and shared dialogues. The case study was developed to strengthen existing productive links with policing and offer real-life collaboration on contemporary police studies. The module has impacted on student learning and has institutionally embraced professional practice in teaching through designing 'academic practice as learning'.
\end{abstract}

\section{Keywords}

Policing, student as producer, collaboration, curriculum design, higher education

\section{Introduction}

This article reflects on the development of collaborative partnerships within teaching and learning in higher education, presenting a case study of a successful partnership between police practitioners and academics in one institution. By applying processes of curriculum design through Student as Producer (Neary and Winn, 2009; Neary et al., 2014), the module examined in this article embraces common themes of shared dialogues, coproduction and transfers of knowledge, in its efforts to develop teaching partnerships with industry.

\section{Corresponding author:}

Katie Strudwick, School of Social and Political Sciences, University of Lincoln, Brayford Pool, Lincoln LN6 7TS, UK.

Email: kstrudwick@lincoln.ac.uk 
In the context of higher education, the introduction of Knowledge Exchange Framework by Research England (2017), working alongside the Office for Students, has developed new metrics and benchmarks to share knowledge and provide comparisons between higher education Institutions (HEIs), measuring their impact on commercialisation and knowledge exchange. With more recent developments with Civic Universities, the shifts in higher education and partnerships can further be recognised, with the author's institution being one of the 30 universities to sign up to the Civic Agreements with the University Partnerships Programme Foundation chaired by Lord Kerslake in 2019 (Brabner, 2019; https:/upp-foundation.org/leading-universities-pledge-commit ment-to-local-communities/). Such reforms demonstrate the commitments towards wider collaborations with the community, through the sharing of knowledge and engagement, and arguably have clear relevance to discussions of policing partnerships in this article.

There have been significant wider drivers towards the professionalisation of policing in England and Wales, from the College of Policing, shown through a number of different forms of police education. Professionalisation is defined by Green and Gates (2014: 75) as 'the transformation of an occupation into a profession' and the fluid nature of it is evident, as recognised by Hough and Stanko (2019) who evaluate the different rationales for professionalision of policing in the United Kingdom, alongside the role of professional knowledge under the leadership of the College of Policing.

The wider acknowledgment of police-academic collaboration/partnerships has been documented by a number of authors in recent years (Fleming, 2010, 2012; Foster and Bailey, 2010; Fyfe and Wilson, 2012; Innes, 2010; Marks et al., 2010; Steinheider et al., 2012), where 'academic inputs' have, as noted by Murji, resulted in a change to both sides through an emerging 'sub field of police studies' (Murji, 2010: 92). Henry and MacKenzie (2012: 326) discuss their knowledge transfer fellowship between academia and policing in Scotland (funded by the Arts and Humanities Research Council). Being developed through the brokering communities of practice model, the authors note the unpredictability of it but reflect on the 'great value' and propose the perspective to be a theoretical resource and framing tool for collaborations in policing. Such transformations have had a noticeable impact on teaching and research, as emphasised and documented, through the special editions of Police Practice and Research (2009 and 2012) and Policing, Policy and Practice (2010).

With the rise of pracademics, policing practitioners who merge into academics (Huey and Mitchell, 2016), there has also been a shift towards broader collaborative partnerships between police forces and HEIs in the United Kingdom. Goode and Lumsden (2016: 76) provides examples of such developments observing East Midlands Policing Academic Collaboration, Scottish Institute for Policing Research, N8 collaboration in the North of England, the Universities' Police Science Institute in Wales, Society of Evidence-Based Policing, among others.

The emerging new routes between police forces and higher education for new police recruits have further been evident, shown with the new Policing Education Qualification Framework (PEQF) (applicable from January 2020) for Police Constable Recruits, encompassing Police Constable Degree Apprenticeship, Degree Holder Entry Programme or a pre-join Degree in Policing (College of Policing https://www.college. 
police.uk/What-we-do/Learning/Policing-Education-Qualifications-Framework/Pages/ Policing-Education-Qualifications-Framework.aspx) and Policing Degree Programmes.

Williams et al. (2019) discuss the relationship between this drive towards police professionalism and police education, under the guise of the new PEQF, addressing the lack of knowledge about the application in practice from the police. Reflections from their study focus on how participants were able to employ their knowledge and critical thinking in their utilisation of learning, while ensuring credibility through learning where the practitioner voice is meaningful and is 'translated into practice to promote enhanced practice' (Williams et al., 2019: 10). Hough and Stanko (2019) also address the value of a degree in policing arguing that given the scale of evidence from America the 'outcomes of decisions about professionalization and graduate entry are likely to be highly contextspecific' (p. 6).

Taking into consideration, the advances in police education and research more globally, Wood (2018:1), in acknowledging the work of Rogers and Frevel (2018: 2), states that developments the United Kingdom have followed 'most Western-style police agencies', while Scott (2010) refers to examples in his support, namely the Wisconsin Case, with Wuestewald and Steinheider (2012) discussing Broken Arrow, Oklahoma Police Department. Buerger (2010: 135) looks to the future arguing that 'progressive police administers are open to such research' with Cordner (2010: 94) asserting that 'police research/police practice relationship is evolving quite positively'. While Engel and Whalen (2010) locate the change in perceptions and relationships between police and academic student and researchers in their article, they reference Bradley and Nixon's work (2009) in Australia 'Dialogue of the deaf'. They propose the end of negative police-academic relationships and affirm the values and positives where 'benefits for both sides are plentiful' (2012: 112), recognising the 'promising partnerships' developing in America. In stating their case supporting police-academic partnerships, the authors base this on operational effectiveness and efficiency; external validity, cooperative transparency and information technology revolution, concluding that we are in a time where 'American policing opens its eyes to the values of academic guidance' (2012: 115).

Hough and Stanko (2019: 7) specifically focus on the United Kingdom highlighting the role of HEIs in the reforms shown with PEQF, stating 'It gives higher education institutions (HEIs) a central role as a co-producer, together with police forces, of learning delivery and assessment of competence', with Wood (2018: 8) concluding that 'The PEQF offers an opportunity for us to rethink what constitutes police knowledge and to reshape policing degrees accordingly'. Such varied illustrations demonstrate the noticeable shift in the role and value of police practitioners in higher education and the wider changing higher education marketplace.

This narrative is a showcase of how a different approach to delivering education has been developed, discussing the experiences from the perspective of the module coordinator in identifying practicalities and pedagogical challenges. 'Police Studies', a thirdyear elective undergraduate module, was developed to strengthen existing productive links with policing and to offer real-life collaboration on contemporary police studies topics. The contribution and impact of this case study have been shown on student learning and on an institutional level, by embedding enterprise and professional practice 
in teaching - in essence, designing 'academic practice as learning'. The discussions in this article further address recommendations drawn from this module framework on how such practices should/could be adopted alongside police practitioners as partners in collaborative learning alongside academics. Such partnerships, referred to as 'pracademics' by Huey and Mitchell (2016), importantly, demonstrate the potential for the value in knowledge sharing between academics and practitioners.

\section{Literature review: Collaborations and partnerships with police practitioners}

The benefits and scale of academic and police practitioner partnerships have been documented by Goode and Lumsden (2016) who reference descriptions of partnerships in Innes work as a 'mirror' or a 'motor' for curriculum development (Innes, 2010: 127, cited in Goode and Lumsden, 2016: 77). Through discussing collaborative and partnership interventions, as functions for change purposes, their writing embraces common themes, which relate to the case study being discussed in this article. The module, Police Studies, represents a shift towards practically embedding practitioners in pedagogical design, so they are part of the learning process, enabling a shared common purpose of enriching critical knowledge for undergraduate students.

Collaborative partnerships between police and academics have common values of embracing the creativeness of shared practices through the identification of joint values, where the benefits to both parties are noteworthy as illustrated in this case study. Adopting a partnership approach to teaching contemporary issues in Police Studies further compliments broader pedagogical aims to enhance critical analytical thinking and the production of independent learners. In essence, although developing such a partnership module raises a number of questions or 'dilemmas' from both sides, discussed later in the article alongside highlighting possibilities, there are numerous positives and justifications to such contributions to higher education.

This article adds to the current established discourse about police-academic collaborations within teaching and research via co-production. Marks et al. (2010) discuss how sharing knowledge with police as 'deliberators' (2009: 114) 'promotes police/ researchers partnerships based on mutual trust, respect and an appreciation of one another's skills and knowledge bases' (2009: 113). Murji (2010), as guest editor of the special edition of policing, highlights that such collaborations are 'commonplace', 'whether at a formal, institutional level or through one- off and ongoing research and consultancy' (2010: 92) and how such collaborations between the police and academia are about 'the purpose of knowledge and research' (2010: 93). With Fleming (2010) and Fyfe and Wilson (2012) addressing some of the challenges with cultural difficulties, alongside the knowledge of 'What works' (2012), explorations of how such partnerships can be shared 'to drive policy in a practical way and evidence-based data that can inform practice' are evaluated (2010: 142). Innes (2010) further explores the wider role and reforms in police research, outlining the differing relationships, namely 'Research by the police, research on the police, research for the police and research with the police' (2010: 128) with each positively facilitating reform and innovative partnerships between police and academia. In all of these discussions, there are considerations of the values within 
such engagement and collaboration with Fleming (2012) noting that 'lessons can be learned' (2012: 376).

As previously addressed, the special editions of the journals Police, Practice and Research (2009 and 2012) and Policing, Policy and Practice (2010) have focused on such developments in police-academic collaborations. Murji (2010) brings together themes within police practitioners and academic collaborative working by exploring the potential to 'stimulate thinking about partnerships in ways that move beyond a 'two worlds' outlook' (Murji, 2010: 92), again highlighting common observations made in relations to the importance of the case study in this article. The special editions address purpose, barriers, roles and benefits, with reflections on sharing good practice alongside representation of differing perspectives of the multitude of factors integral to establishing and maintaining such partnerships.

\section{Models of teaching: Student as Producer}

The module's teaching and learning strategy was grounded in Student as Producer, seeking to address key issues on contemporary policing, through a theoretical and practical lens, by the involvement of contemporary representations of research and practice in the field of policing. The Student as Producer model itself, originally developed by Mike Neary at Warwick in 2004 and then at Lincoln in 2010, provides a wider critique towards the marketisation of higher education and redefines the relationship between the academic and student. Globally recognised as a critical curriculum design, it enables students to learn by engagement with academics in research projects, with the model placing values of partnerships and active collaboration as fundamental.

The development of Student as Producer, as a critical research engaged teaching model, has been adopted in many universities and has been institutionally embedded in teaching and learning strategies in my institution. By providing a critique of the now very recognisable role of the 'student as consumer', the model embraces the ownership of learning by embedding employability, softer skills (confidence, self-belief and esteem) and working towards enhancing participation from students.

One of the central tenants to the design of Police Studies module was the active engagement of students in the critical application of their learning, which encompasses core values to Student as Producer ethos. Fundamental to this model of teaching and learning is the place of students, as highlighted by Neary et al. (2014: 8) 'where undergraduate research is produced in collaboration with other students and with academics as part of the curriculum ...'. This was demonstrated in this module by the engagement in partnerships and the integral nature of this to the learning approaches, noted by Strudwick (2017: 75) where 'meaningful participation' in learning enables a 'reshaping effectively demonstrates to students the benefits of skills, knowledge, and engagement within a culture of partnerships on teaching and learning'. It was the interactive nature of the workshops, essentially matching the broad aims for learning, and meeting the objectives from police partners as well as the module coordinator, which were important in the development of Police Studies. With key emphasis on active engagement between all parties, with a shared ethos and values, for both the Police and the Students, there was clear application of Student as Producer principles, with 'research engaged teaching and 
learning as the underpinning principle for all curriculum development' (Hagyard and Watling, 2012: 79).

In addition to embracing Student as Producer, teaching the module design for Police Studies further embedded collaboration and partnerships. Such aspects of teaching and learning models have also been identified as being part of Student as Partners models of teaching (see writings from Bovill et al., 2015; Healey et al., 2014a, 2014b; and Matthews et al., 2017). There are evident links between Student as Producer and Student as Partners models or students as collaborators (Bovill et al., 2011), with such models each embracing similar aims and ethos of collaboration and co-creation (see Bovill et al., 2015; Curran, 2017; Zepke, 2019; Zepke and Leach, 2010). Most important is the role that students have in their learning journey, which was core to the success of the Police Studies module.

The positives of developing the partnership approach with police practitioners on a regular weekly basis through workshops enabled consistent engagement opportunities for students as active partners of the module. The Police Studies conference at the end of the module further illustrates the benefits and positives for all involved in the module, shown with practitioners engaging with students through their individual posters, often leading to further additional support being offered by practitioners for more resources. Student as Producer offers a critique of student as consumer and an appreciation of/for student engagement and participation in research engaged teaching (notably including partnerships, community, students as scholars, researchers and 'partners in our learning'; Healey et al., 2015:150) as shown in students' experiences of this module. Experiences attained from this module for the coordinator, the students and the practitioners have over the last 3 years emphasised good practices of partnerships, transformation, powersharing relationships and inclusive partnerships (Matthews, 2017: 2).

In the module design for Police Studies, there was an important central place for students which would impact upon their learning journey. This can be shown with assessment for the module being twofold, an essay and a poster presented at Police Headquarters in an externally facing policing conference, to police practitioners as partners and a wider audience of policing professionals. The assessment formats of the module focused upon student identity and developing their role as producer and collaborator. Student as Producer was the overriding ethos framing this redesign and development of collaboration, with students producing knowledge within their assessment and engagement on the module.

For the purpose of this article and the design of this module, Student as Producer was considered alongside how it relates to critiquing the commodification of higher education. Jameson et al. (2012a: 10) address the values of Student as Producer as a teaching and learning model with the potential to transform and enhance learning, arguing 'student as producer requires students to collaborate with academic staff in the production of knowledge from within, rather than judge it from the outside'. This ethos became important for considering how teaching can be framed in alternative ways, such as through collaborative teaching.

Neary and Winn (2009: 11) further reflect on how Student as Producer is more than just redesigning the curriculum but offers a challenge to the consumerism of learning through the production of knowledge which promotes 'openness, enquiry, ownership and 
empowerment'. Such values were key to the coordinator's plans for this module, seeking to shift the roles of students to be both producers, but also collaborators, on a partnership level with practitioners and academics. This was shown with the engagement and collaboration demonstrated in the Policing conference marking the conclusion to the module. In this sense, students became the producers of knowledge, developing their learning that had been supported and facilitated by the police practitioner workshops and joint partnership working with academic tutor.

Part of the pedagogical ethos was further taken from the strengths of knowledge sharing and the place that practitioners can have in this role. The importance of different types of knowledge and the benefits of sharing such knowledge allows for more than just a redesign but makes the efforts to mend or shift the tensions between practice and academia. Fullwood et al. (2018: 2) discuss how enhancing knowledge by sharing between organisations raises organisational culture as both an 'enabler and a barrier' to knowledge sharing. This potential driver was important for the development of Police Studies, especially given the differences between the organisational culture of academia and the well-documented Police culture (see Banton, 1964; Chan, 1997; Reiner, 1992; Skolnick, 1966).

\section{Where it began - The development of Police Studies}

The Police Studies module advanced from my established role as an academic 'critical friend' for the force. Opportunities enabled both parties to extend collaborations into teaching which were seen to have mutual benefits for the police and university tutors involved with the module. Previously my role as a critical friend was to offer expertise on police-led evaluations; however, this has been accompanied with an appetite from the police for critical debate and academic rigour. According to Waddington (2010), critical friends within policing have much to offer, arguing that despite identifying them as being in a 'marginal position', they are able to give an independent objective critique which represents 'what critical friendship means in practice' (2010: 125). This came from both sides in this module. Goode and Lumsden (2016: 84) further discuss successful police and academic collaborations, where 'academic partners... [are] ... seen to offer a robustness that has been lacking...' '. Such positive reflections coincide with my experiences as module coordinator.

The Police Studies module was developed for a third-year undergraduate cohort, initially in 2016, as an optional module for students studying Criminology, Sociology, Social Policy, Politics or International Relations. The key aim was 'To provide a specialist exploration of contemporary issues in policing involving the application of knowledge in a problem solving operational context'. The module addressed specific organisational and political challenges faced by the police in the 21 st century, examining the myriad of issues that shape formal police responses under specific themes set on a weekly basis. In designing policing themes on selected topics, there was a need for clear communication channels between the module coordinator and the police. Communication, according to Fleming (2010), has been identified as one of the core issues which may have an impact on academic and police partnerships, alongside negotiation and understanding. Foster and Bailey (2010: 101) further discuss the benefits and demands 
within police and academic collaborations referring to the challenges of 'finding a language' and 'the right people'. Such dilemmas were central to the planning and organisation of this partnership teaching model. When considering partnership approaches to teaching in their writing, Fullwood et al. (2018) highlight that sharing knowledge between organisations involves core factors such as reciprocity and trust. These influential factors, in my experience, came from working collegially with interested people from the organisation and fostering mutual values and goals in the collaboration.

\section{Experiences of designing Police Studies}

This module was developed within a university externally recognised for placing students as its central vision, by embedding Student as Producer and exemplifying good practices within student experiences and learning. Experiences discussed in the article highlight the values of sharing new critiques via partnerships between academics and practitioners, showcasing what they can offer and demonstrating how such possibilities can enhance learning developments by sharing good practice within the challenging discipline of criminology.

Core to this academic journey were the aspirations of the author to embed practitioner impact into academic learning. One of the central tenets was to ensure planning through organisational commitment, and engagement, from both sides, police and academics. Further to this, there was a necessity to also get the students engaged and 'committed' in the partnership, by being part of the joint ethos for this module. Students needed to be engaged and be ready to take some ownership over the developments of the module, both by helping future cohorts through literature scoping, but also on an external enterprise level, by engaging in a professional manner with the practitioners each week.

By embracing the potential values of such collaborations, namely the promise of knowledge transfer, shared dialogues and common ground, collaborations were developed to provide commitment from the module coordinator shown through good innovative practice within teaching and learning. The role that students play in their learning, within the context of a highly marketised system of higher education, has been discussed by Serrano et al. (2018) in their evaluation of authenticity in learning. Such critical pedagogical reflections are relevant to this case study placing students as core to the continued development of this module, its learning outcomes and meeting the challenges of creating greater authenticity for creative forms of learning and assessment. The influence of applying Student as Producer within Police Studies also ensured that 'Undergraduate[s] became recognised as an integral part of the academic project of their institution' (Neary and Saunders, 2016: 2)

In addition to reaping the benefits from collaborations, the design of the module further set out clear expectations for the students themselves to be engaged in the planning and design, through the use of OneNote, a Microsoft organisational learning tool to share and collaborate notebooks, as a supplementary learning aid alongside Blackboard, an online learning platform. The module was organised around interactive workshops on different themes or topics, with each one requiring reflective student engagement on core issues and debates to be electronically added to OneNote following 
each session. The use of OneNote allowed for a two-way engagement between the module coordinator and the students, with personalised feedback and access to updated academic reading through Talis reading lists, a digitisation system for learning. It was important that students knew they were part of the design and development of the module, especially given the overriding ethos and academic rationale, for this collaborative module to embrace and enhance co-learning and demonstrate that scholarship can be disseminated from good practice.

It was imperative that creative forms of learning were incorporated in this case study, reflecting the considerations of Stentoft (2017: 53) in their work on interdisciplinary and problem-based learning where 'students engage to integrate knowledge derived from several disciplines to construct new perspectives on a particular problem or scenario'. Students studying Police Studies were able to gain knowledge from different forms of practitioner knowledge on all aspects of policing, including those from senior leadership with sessions from the Police Crime Commissioner (PCC) on governance. The students were also able to learn about civilian perspectives on mental health, multi-agency collaboration and personal reflections on sexuality. In essence, the curriculum design sought to show that mixing academic theory and practice has dividends for students' development and skills.

Part of the rationale for student engagement with OneNote was to enhance their skills but also to give them greater ownership over their learning journey. In the second year of teaching this module, the assessment criteria were redesigned to include a participation mark of $10 \%$ (one that included both attendance but also measured levels of participation and engagement from students). The participation mark collectively made up the assessment criteria alongside $90 \%$ for the individual essay. By utilising students' knowledge through the participation mark and their engagement further supports the Student as Producer ethos, enabling students to be the producers of knowledge and active partners, which provides critique to student as consumer and 'encourages the development of collaborative relations between the student and the academic in the production of knowledge' (Neary and Winn, 2009: 209).

Student as Producer, underlined by principles of critical pedagogy, has notably advanced the critique against the consumerism of higher education. Neary and Saunders (2016: 2) discuss Student as Producer, as an 'organising principle for curriculum development, but identify that it goes beyond student engagement and is 'more than a curriculum development project'. It was indeed this potential of developing academic knowledge production within a collaborative partnership that allowed the principles to be applied to the case study of Police Studies.

Student submissions, under the participation mark, were stored in OneNote. Submissions required individual student reflections through peer learning on different types of informal submissions, including the design and planning of a 'resource pack' for future cohorts, a group framework posters on conceptual issues within policing, a declaration of policing on a regional, national and global level and an individual reflective policing portfolio. Again, the commitment shown by students through being part of the fabric of the module also has similarities with the established work on Student as Partners (see Cook-Sather and Felton, 2017; Healey et al., 2014a, b; Healey et al., 2015; Healey et al., 2016). Matthews et al. (2017: 3) further discuss students' perceptions of being involved 
in partnerships, through peer learning and assessment, and outline the importance of a sense of belonging arguing 'these practices can be transformative and beneficial for both students and staff'. Student submissions collectively formed a learning resource pack, which could be added to by peers throughout the module.

\section{Core characteristics of police academic collaborations}

Essential elements and core factors, learnt through experiences as module coordinator, enabling the continuation of the Police Studies module are outlined in the following section and discussed as 'lessons learnt'. Taking into consideration the core principles of Student as Producer (including collaboration, partnerships, active engagement, among others), the following reflection focuses on police and academic partnerships in teaching and provides wider literature to support experiences.

Murji (2010: 94) addresses the purpose and processes of academic and police collaborations highlighting the usefulness of such partnerships, ' ... it is the process of working together that is most significant in shaping results'. Experiences learnt with Police Studies planning, and through acting as a critical friend, enable the author to appreciate the function of such collaborations as part of the police-research mapping acknowledged by Innes (2010: 128)

research with the police is a more collaborative and co-productive endeavor that seeks to find ways for researchers and police staff to work together to address a particular issues or problem.

The Police Studies module combined practitioner knowledge, within a broader learning experience, enabling students to benefit from this reflective collaborative teaching approach. In this sense, it is essential that 'the right people' were part of the partnership and were integral in decision-making for the module topics. Such contemporary areas of focus over the last 2 years have included policing abuses, ethical policing, public order, values within policing, threat, risk and vulnerability, governance role of the PCC, online vulnerability and sexual offending. In this role, police practitioners became partners or, according to Coxhead (2018: 22) in his review of the Police Studies module, 'advanced practitioners'. In recognising a shift to their role, through working in partnership with academia, the module was seen to demonstrate 'how academic skills can be taught and demonstrated while applying the effort to 'real world' problems' (2018: 22).

Following approximately 2 years of development and planning by both parties, prior to validation, there were clear commonalities between the module coordinators experiences and those conversed in the established literature on police academic collaborations (see Special editions of Police, Practice and Research (2009 and 2012) and Policing, Policy and Practice (2010)). Such journal issues identify the importance of shared dialogues (Marks et al., 2010; Murji, 2010) and teamwork and mapping the terrain (Fleming, 2012), all of which were valuable for the development of reciprocal relationships built on shared common values. Mutual objectives and a bond of trust between 'both sides' were further demonstrated allowing for this new form of practitioner and academic development with the Police Studies module. 
By merging police practice knowledge and academia to enhance the curriculum, there was an active promotion of students as independent learners, and when accompanied with Student as Producer ethos, this provides reciprocal benefits for all parties. Reflecting on the challenges of teaching with practitioners on a disciplinary level, Jameson et al. (2012b) consider creative engagements alongside values of critical thinking within criminology. By addressing the reflective importance for students to relate to their learning journey, and importantly their stake in it, changes from curriculum design have real potential. This is especially true within criminology, a discipline of fluidity which has differences in its theoretical foundations and competing knowledges, hence one size does not fit all.

Through identifying with contributions in the literature, critiques of how such collaborations have grown enables reflections on 'what works' to be in accordance with themes mirrored within experiences as module coordinator for the Police Studies module. Marks et al. (2010) discuss the importance of shaping police and academic collaboration and the values of dialectical relationships. By noting the challenges and the possibilities, their discussions highlight observations that were also evident in the Police Studies module evaluations from students (16/17 and 17/18). For instance, addressing the benefits of bringing together different perspectives through mutual trust - in effect 'two worlds' (Marks et al., 2010).

Qualitative student comments, reported by Coxhead (2018: 23), identified similar values within their reflections of what the partnership approach offered them:

Beyond traditional studies, its been really interesting seeing policing practice and culture first hand. You get to discuss with professionals the nuances and implications of cases in a greater depth than just reading about them. (Student)

The importance of involving police in academia, according to Fleming (2010), enables an appreciation of what the police do and practice...(2010: 141), this was also recognised in this case study of Police Studies module and student reflections.

Observations from Marks et al. (2010: 114) of the police as 'deliberators and knowledge producers' were further supported by Foster and Bailey (2010) in their recognition of prerequisites for collaboration (trust, openness and honesty). Such characteristics have been recognisable in the partnerships models of Police Studies, especially in relation to the topics of the workshop sessions. Foster and Bailey (2010) also refer to 'mutual education' and the importance of commonality of themes within policing. It is through embracing creativeness within new perspectives from both police and academics, that diversity and divergences are celebrated in the bringing together of 'both worlds', while further supporting positive benefits of engagement and collaboration.

Literature from Fleming (2010, 2012), Foster and Bailey (2010), Fyfe and Wilson (2012) and Marks et al. (2010) demonstrates that police academic partnerships can work, both in practice, and on a methodological level, and that they have the potential to result in shifts from partnerships that can shape the policing agenda. In these writings, reflections focus on the importance of collaborative partnerships and 'teamwork' (Fleming, 2012: 375), while also 'building relationships of trust, openness and honesty, establishing good personal relationships...' (Fyfe and Wilson, 2012: 306). 
Lessons learnt from experiences of police-academic collaborations indicate that successes are dependent upon a combination of factors, which enable the co-production of knowledge. According to Steinheider et al. (2012: 369), this includes mutual trust, respect and open communication and 'trust with their collaboration partner'. Wuestewald and Steinheider (2009: 110) further reflect on their case study which showed that professional development and dialogues can be innovative when 'focusing on common interests and shared vision may be more important than dwelling on differences', thus advocating a sharing of paths and disciplines. When acknowledging trends within police and academic partnerships, there are clear similarities with key principles from teaching models and curriculum design, namely Student as Producer. Involving core elements of shared partnerships, collaboration, active participation and a sharing of knowledge, all are integral to the success of collaborative partnerships between academia and practice, as shown in this case study.

Interestingly, there have been other recognised forms of partnerships and collaborations between academics and policing. Huey and Mitchell (2016: 300) provide a commentary of Pracademic - practitioners (in this context policing practitioners) who merge into academics as those 'intended to signify someone who straddles to, often very different, and sometimes conflicting worlds'. Through identifying the emergence of the police pracademic values and illustrations of knowledge production, there was an acknowledgment that such partnerships are becoming more frequent. Experiences, as module coordinator, have shown that there were indeed clear benefits with Police Studies with its duel purposes of producing new knowledge between academia and policing. A sharing of knowledge and practice also illustrates an opportunity to provide a sense of greater critical rigour to issues within contemporary policing.

Literature has considered some of the limitations and barriers to police-academic collaborations, as shown in the work of Goode and Lumsden (2016). However, in his review of the Police Studies module, Coxhead (2018) refers to the important role that students play in such collaborations, identifying they can offer

a wealth of rapid evidence reviews of what is out there ... often with new insights, and offer it back in a user-friendly summary for those very same busy practitioners. (2018: 22)

Such recognition of the value for academia, policing practitioners and students through their learning journeys was also acknowledged by the Chief Constable, who saw the partnership model of Police Studies as 'inspiring' with students with 'inquisitive minds' that

combined working with practitioners on key topics offering a great way of bringing in fresh perspectives, as well as showing to the students some 'real world' perspectives. (cited in Coxhead, 2018: 23)

As module coordinator, the benefits and contribution of this case study for enhancing curriculum design are clear. Discussions in this article have indicated the evident potential which can be associated with developing and sharing knowledges via active partnerships with practitioners in collaborative learning, to learn about 'both worlds'. For 
students, as independent learners, active partners or producers of knowledge, the benefits are also obvious, this is best evidenced with a comment cited by Coxhead (2018) from one of the students studying Police Studies:

Getting the insight into the role of PCC was priceless knowledge for me, I got far more insights from that than reading journals as there is not much academic literature about rural crime published. (2018: 23)

\section{Conclusion}

As module coordinator concluding with a series of recommendations for how this practice should/could be adopted, empathises the positives of designing new modules, which embrace different approaches to learning.

Firstly, ensuring that there is commitment and 'buy-in' from both sides. This enables the benefits of the relationship between policing and academia to provide an opportunity for more enhanced, directed, critical rigour to issues within contemporary policing.

Secondly, the agreement of a shared interest between partners is essential for mutual trust to develop. This often emerged through a common vision of the reciprocal positives of collaborations for all parties and the reasons for sharing knowledge between policing and academia. All parties need to recognise their value in the collaboration (academics, practitioners and students), although these may differ they need to be identified early to empathise the cooperative nature of the relationship.

Thirdly, it is important to overcome some of broader challenges arising with collaborations, these often led to 'ongoing' amendments from both sides during the preparation and early stages. The core element to working with partners is open communication and ensuring trust, in my experiences these enabled the partnership to continue to flourish.

Fourthly, logistically, it is mindful for the module coordinator to be fairly flexible with the finer details of module design when preparing the module, these include specific lecture titles which can be decided upon once topics have been agreed. Part of this does mean as module coordinator and for police partners that you have confirmation of dates/ rooms as early as possible. Part of my experiences meant this often depended on the context, with decisions made earlier with police partners but later in an academic context.

Fifthly, ensuring that students are informed about the characteristics of the module and the extent to which partnership modules with practitioners ensure that 'both sides' are represented. From my experiences, this meant that there needed to be academic input throughout the module, with specific academic-led workshops at core points to enhance the theoretical and conceptual themes raised by practitioners.

Finally, commitment, enthusiasm and dedication are required from all involved in the module. For students, this was addressed to some extent by the introduction of the participation element of the assessment mark. For the module coordinator, this often meant, at times, encouraging active participation and engagement in workshops, 
ensuring tasks were interactive and challenging, while also allowing practitioners to have oversight and ownership of their sessions.

This article has reflected on experiences with the Police Studies module, both through police academic partnerships and pedagogically with Student as Producer. The creative ways of engaging students with practitioners have been discussed, while enhancing and embedding core principles of Student as Producer, collaboration, shared knowledge and active learning. Student feedback can often offer insightful reflections, which highlight the importance of continuing to strive for alternatives ways of teaching. In these module evaluations, students made references to core elements, notably the 'different and innovative opportunities' offered by the module, the importance of the participation mark and the appropriateness of the conference to finish the module, emphasising their recognition of the collaborative and partnership elements to the module.

One of the final messages, as module coordinator, to come out of this experience was not to be risk-averse in our roles within teaching and learning but to continue to strive to produce stimulating and challenging student-centred learning within an increasingly marketised higher education system.

\section{Declaration of conflicting interests}

The author(s) declared no potential conflicts of interest with respect to the research, authorship, and/or publication of this article.

\section{Funding}

The author(s) received no financial support for the research, authorship, and/or publication of this article.

\section{ORCID iD}

Katie Strudwick (D) https://orcid.org/0000-0002-0733-2572

\section{References}

Banton M (1964) The Policeman in the Community. London, UK: Tavistock.

Bovill C, Cook-Sather A and Felten P (2011) Students as co-creators of teaching approaches, course design and curricula: implications for academic developers. International Journal for Academic Development 16(2): 133-145.

Bovill C, Cook-Sather A, Felton P, et al. (2015) Addressing potential challenges in co-creating learning and teaching: overcoming resistance, navigating institutional norms and ensuring inclusivity in student-staff partnership. Higher Education 71: 195-208. Available at: http:// eprints.gla.ac.uk/107084/ (accessed 1 May 2019).

Brabner R (2019) Over 30 universities sign new "civic university agreement" to reaffirm local role, civic university commission UPP. Available at: https://upp-foundation.org/leading-univer sities-pledge-commitment-to-local-communities/Leadinguniversities pledge commitment to local communities (accessed 1 May 2019).

Buerger ME (2010) Policing and research: two cultures separated by an almost-common language. Police Practice and Research 11(2): 135-143.

Chan J (1997) Changing Police Culture. Cambridge, UK: Cambridge University Press. 
College of Policing Available at: https://www.college.police.uk/What-we-do/Learning/PolicingEducation-Qualifications-Framework/Pages/Policing-Education-Qualifications-Framework. aspx (accessed 1 May 2019)

Cook-Sather A and Felton P (2017) Where student engagement meet faculty development: how student-faculty pedagogical partnerships foster a sense of Belonging. Student Engagement in Higher Education Journal 9(2): 3-11.

Cordner G (2010) Guest editors introduction the evolving relationship between police research and police practice. Police Practice and Research 11(2): 90-94.

Coxhead J (2018) Learning together. Police Professional 14: 22-23.

Curran R (2017) Students as partners-good for students, good for staff: a study on the impact of partnership working and how this translate to improved students-staff engagement. International Journal for Students as Partners 1(2): 1-16.

Engel RS and Whalen JL (2010) Police-academic partnerships: ending the dialogue of the deaf, the Cincinnati experience. Police Practice and Research 11(2): 105-116.

Fleming J (2010) Learning to work together: police and academics. Policing: A Journal of Policy and Practice 4(2): 139-145. Available at: https://doi-org.proxy.library.lincoln.ac.uk/10.1093/ police/paq002 (accessed 30 January 2019).

Fleming J (2012) Changing the way we do business: reflecting on collaborative practice. Police Practice \& Research 13(4): 375-388, 14.

Foster J and Bailey S (2010) Joining forces: maximizing ways of making a difference. Policing. Policing: A Journal of Policy and Practice 4(2): 95-103. Available at: https://doi-org.proxy. library.lincoln.ac.uk/10.1093/police/paq007 (accessed 30 January 2019).

Fullwood R, Rowley J and McLean J (2018) Exploring the factors that influence knowledge sharing between academics. Journal of Further and Higher Education 43(8): 1051-1063.

Fyfe N and Wilson P (2012) Knowledge exchange and police practice: broadening and deepening the debate around researcher-practitioner collaborations. Police Practice and Research 13(4): 306-314.

Goode J and Lumsden K (2016) The McDonaldisation of police-academic partnerships: organisational and cultural barriers encountered in moving from research on police to research with police. Policing and Society 28(1): 75-89.

Green TY and Gates A (2014) Understanding the process of professionalisation in the police organisation. Police Journal: Theory, Practice and Principles 87(2): 75-91.

Hagyard A and Watling S (2012) The student as scholar: research and the undergraduate student. In: Neary M, Stevenson H and Bell L (eds), Towards Teaching in Public Reshaping the Modern University. London, UK: Contiuuum, pp. 68-83.

Healey M, Bovil C and Jenkins A (2015) Students as partners in learning. In: Lea JM (ed.), Enhancing Learning and Teaching in Higher Education. Milton Keynes: Open University Press, pp. 4-76.

Healey M, Flint A and Harrington K (2014a) Engagement Through Partnership: Students as Partners in Learning and Teaching in Higher Education. York: The Higher Education Academy.

Healey M, Flint A and Harrington K (2014b) Students as Partners in Learning and Teaching in Higher Education. York: Higher Education Academy. Available at: Http://www.heacademy. ac.uk/systems/files/resources/engagmebt_through_partnership.pdf (accessed 30 January 2019). 
Healey M, Flint A and Harrington K (2016) Students as partners: reflections on a conceptual model. Teaching \& Learning Inquiry 42: 1-13.

Henry A and MacKenzie S (2012) Brokering communities of practice: a model of knowledge exchange and academic-practitioner collaboration developed in the context if community policing. Police Practice and Research 13(4): 315-328.

Hough M and Stanko E (2019) Designing degree-level courses for police recruits in England and wales: some issues and challenges. Policing: A Journal of Policy and Practice. Available at: https://doi.org/10.1093/police/pay096

Huey L and Mitchell R (2016) Unearthing hidden keys: why pracademics are an invaluable (if underutilized) resource in policing research. Policing: A Journal of Policy and Practice 10(3): 300-307. Available at: https://doi-org.proxy.library.lincoln.ac.uk/10.1093/police/paw029 (accessed 30 January 2019).

Innes M (2010) A 'mirror' and a 'motor': researching and reforming policing in an age of austerity. Policing: A Journal of Policy and Practice 4(2): 127-134. Available at: https://doi-org.proxy. library.lincoln.ac.uk/10.1093/police/pap058 (accessed 30 January 2019).

Jameson J, Jones M and Strudwick K (2012a) Browne, employability and the rhetoric of choice: student as producer and the sustainability of HE. Enhancing Learning in the Social Sciences 4(3): 1-15.

Jameson J, Strudwick K, Bond-Taylor S, et al. (2012b) Academic principles versus employability pressures: a modern power struggle or a creative opportunity? Teaching in Higher Education 17(1): 25-37.

Marks M, Wood J, Ally F, et al. (2010) Worlds apart? On the possibilities of police/academic collaborations. Policing: A Journal of Policy and Practice 4(2): 112-118, Available at: https:// doi-org.proxy.library.lincoln.ac.uk/10.1093/police/pap033 (accessed 30 January 2019).

Matthews K (2017) Five propositions for genuine students as partners practice. International Journal for Students as Partners 1(2). Editorial Available at: https://doi.org/10.15173/ijsap. v1i2.3315 (accessed 1 May 2019).

Matthews K, Groenendijk L and Chunduir P (2017) We want to be more involved: student perceptions of students as partners across degree program curriculum. International Journal For Students as Partners 1(2): 1-16.

Murji K (2010) Introduction: academic-police collaborations - beyond 'two worlds'. Policing: A Journal of Policy and Practice 4(2): 92-94.

Neary M, Saunders G, Hagyard A, et al. (2014) Student as Producer Research-Engaged Teaching, an Institutional Strategy. York: The Higher Education Academy.

Neary M and Saunders G (2016) Student as producer and the politics of abolition: making a new form of dissident institution? Critical Education 7(5): 2-23.

Neary M and Winn J (2009) The student as producer: reinventing the subject experience in higher education. In: Bell L, Stevenson H and Neary M (eds), The Future of Higher Education: Policy, Pedagogy and the Student Experience. London, UK: Contiuuum, pp. 192-210.

Reiner R (1992) The Politics of the Police. Oxford, UK: Oxford University Press.

Rogers C and Frevel B (2018) 'Introduction: Higher Police Education-An International Perspective'. In: Rogers Colin and Bernhard Frevel (eds) Higher Education and Police. An International View. Cham, Switzerland: Springer International, pp. 1-14.

Scott MS (2010) Policing and police research: learning to listen, with a Wisconsin case study. Police Practice and Research 11(2): 95-104. 
Serrano M, O’Brian M and Roberts K (2018) Critical pedagogy and assessment in higher education: the ideal of 'authenticity' in learning. Active Learning in Higher Education 19(1): 9-21. Skolnick J (1966) Justice Without Trial. New York, NY: Wiley.

Stentoft D (2017) From saying to doing interdisciplinary learning: is problem-based learning the answer? Active Learning in Higher Education 18(1): 51-61.

Steinheider B, Wuestewald T, Boyatzis R, et al. (2012) In search of a methodology of collaboration: understanding researcher-practitioner philosophical differences in policing. Police Practice and Research 13(4): 357-374.

Waddington PAJ (2010) Police pursuits: a case study of 'critical friendship'? Policing: A Journal of Policy and Practice 4(2): 119-126. Available at: https://doi-org.proxy.library.lincoln.ac.uk/ 10.1093/police/pap057 (accessed 30 January 2019).

Williams E, Norman J and Rowe M (2019) The police education qualification framework: a professional agenda or busing professionals? Police Practice and Research 20(3): 259-272. DOI: $10.1080 / 15614263.2019 .1598070$.

Wood D (2018) Embedding learning and assessment within police practice: the opportunities and challenges arising from the introduction of the PEQF in England and Wales. Policing: $A$ Journal of Policy and Practice. Epub ahead of print 5 November 2018. https://doi.org/10. 1093/police/pay087.

Wuestewald T and Steinheider B (2009) Practitioner-researcher collaboration in policing: a case of close encounters? Policing: A Journal of Policy and Practice 4(2): 104-111. Available at: https://doi-org.proxy.library.lincoln.ac.uk/10.1093/police/pap035 (accessed 30 January 2019).

Zepke N (2019) Student engagement research 2010-2018: continuity and emergence. Advance. Available at: Http://advance.sagepub.com/articles/Student_Engagemebt_Resarch_2010-2018_ continuity_and_emergence/7871984 (accessed 1 May 2019).

Zepke $\mathrm{N}$ and Leach L (2010) Improving student engagement: ten proposals for action. Active Learning in Higher Education 11(3): 167-177. 